\title{
$\therefore$ \\ Immediate Heart Rate Response to Standing in Pregnancy: A Case Control Study from India
}

IJCRR

Section: Healthcare

ISI Impact Factor

(2019-20): 1.628

IC Value (2019): 90.81

$\operatorname{SJIF}(2020)=7.893$

(c) (7) (8)

Copyright@IJCRR

\section{Balasaheb B. Vikhe ${ }^{1}$, Shashikant B Sabade², Muktpal M. Bhalerao³}

'Associate Professor, Department of Physiology, Rural Medical College, Loni, Maharashtra, India; ${ }^{2}$ Associate Professor, Department of Physiology, Rural Medical College, Loni, Maharashtra, India; ${ }^{3}$ Assistant Professor, Department of Physiology, Rural Medical College, Loni, Maharashtra, India.

\section{ABSTRACT}

Introduction: During pregnancy various changes occurs in sympathetic and parasympathetic functions in pregnant woman. Sometime these changes may be beneficial for pregnant woman or sometimes these changes may create health problems. But most important thing is in pregnant woman the normal values for these parameters may altered as compare to non-pregnant woman and must be thoroughly evaluated before therapeutic intervention. These changes are initiated by various hormonal changes during pregnancy and also due to mechanical pressure exerted by growing fetus during pregnancy.Study of parasympathetic functions during pregnancy help to predict any pre-existing autonomic dysfunction.

Objective: To study one of the parasympathetic function test i.e immediate heart rate response to standing also known as $30: 15$ ratio in pregnant woman from rural population of India.

Methods: A case control observational study was carried out in the department of Physiology in collaboration with Obstetrics and Gynecology department at Rural Medical College Loni. Total four hundred eighty subjects selected for study. Subjects were divided in to one hundred twenty non-pregnant and one hundred twenty pregnant women in each trimester of pregnancy. Immediate heart rate response to standing was studied on "CANWIN- Cardiac Autonomic Neuropathy Analyzer". Data was analyzed using ANOVA test and multiple comparison analysis.

Results: A significant decrease in immediate heart rate response to standing $(p<0.05)$ observed in pregnant women as compared to non-pregnant women.

Conclusion: The study showed a significant decrease in immediate heart response to standing in normal pregnant women as compared to non-pregnant women from the rural population of India. A study of parasympathetic functions must be done to predict any pre-existing autonomic dysfunction during pregnancy.

Key Words: Heart rate, Parasympathetic function, Pregnancy, CANWIN

\section{INTRODUCTION}

Pregnancy is one of the most beautiful and enriching experiences in a woman's life. It is characterized by various changes in the functions of the various regulatory system of the human body. These changes are initiated by ovarian and placental hormones during the first trimester and get modified as gestational age advances. Significant physiologic adaptations take place in the body long before they are necessary. By the seventh week of pregnancy significant changes observed in overall body compositions as well as cardiopulmonary and metabolic functions. ${ }^{1}$ The decline in systemic vascular resistance may be due to gestational hormones, increased concentrations of prostaglandins, and increased heat production due to developing fetus and development of a low-resistance circulation in the pregnant uterus. ${ }^{2}$

An increase in heart rate is observed as early as from the $15^{\text {th }}$ week of gestation. Pregnancy is associated with an increase in blood volume due to a marked increase in plasma volume. This increased blood volume results in increased cardiac output during pregnancy. The asynchronous increase in heart rate and stroke volume results in marked augmentation of cardiac output during pregnancy. The parasympathetic deactivation towards term may also contribute to increased heart rate and cardiac output at rest in pregnancy. ${ }^{3}$ It is observed in earlier studies that in non-pregnant women, both systolic and diastolic blood pressure increases

\section{Corresponding Author:}

Dr. Muktpal M. Bhalerao, Assistant Professor, Department of Physiology, Rural Medical College, Pravara Institute of Medical Sciences Loni, Tq: Rahata Dist: Ahemadnagar 413736, (MS), India; Mobile: 9689320134; E-mail: drmmbhalerao2017@gmail.com

ISSN: 2231-2196 (Print)

Received: 05.09 .2020
ISSN: 0975-5241 (Online)

Revised: 12.11 .2021
Accepted: 23.12 .2021
Published: 07.05 .2021 
immediately on standing and returned to basal level within 10 minutes, while in the case of pregnant women, both systolic and diastolic blood pressure decreases on standing. A reduction in the oscillation of right atrial distension from diminished pulsatility of a venous return due to the growing uterus may be responsible for lowering diastolic blood pressure in pregnancy. It was also observed that the Valsalva manoeuvres ratio in pregnancy followed a downward trend from early to late pregnancy. It is most probably due to physiologic adaptation to chronic volume overload during pregnancy. ${ }^{4}$ Pulse rate remained unchanged in both pregnant and non-pregnant woman. Heart rate response to standing expressed as postural stress test was observed to remain unaltered during early pregnancy but significant reduction in postural stress test was found during last trimester. ${ }^{5}$ But in another study no change in heart rate responses observed in the pregnant woman. Though in the same study blood pressure changes were slightly weaker in a pregnant woman as compared to a non-pregnant woman. ${ }^{6} \mathrm{An}$ incomplete adaptation in the cardiovascular system during early pregnancy may be the cause of this deranged cardiovascular parameter in the pregnant woman. It has been observed that the increase in blood volume during the second half of pregnancy result in improved hemodynamic stability. ${ }^{7}$

As from earlier studies, it is not clear whether there is any change in heart rate or immediate heart response to standing during pregnancy or it remains unaffected. So we planned a study with aim of evaluating of immediate heart response to standing in pregnant women and compare it with non-pregnant women.

\section{MATERIALS AND METHODS}

A case-control observational study was carried out in the Department of Physiology in collaboration with the Obstetrics and Gynecology department at Rural Medical College Loni from India. The study was carried out after the approval from Institutional Ethics Committee with Registration No. PMT/ PIMS/RC/2013/226.

A total of four hundred eighty women aged from 20 to 30 years without any recent history of cardiorespiratory diseases was selected. Among the total participant, three hundred sixty were pregnant in the case group and one hundred twenty were non-pregnant in the control group. The case group was further divided into three trimesters $1^{\text {st }}$ trimester, $2^{\text {nd }}$ trimester, and $3^{\text {rd }}$ trimester with one hundred twenty subjects in each trimester.

\section{Inclusion Criteria:}

Age group 20 to 30 years.

Pregnant women visiting the hospital for a routine checkup.
Free from any systemic illness which can affect cardiovascular function.

Able to complete the tests for the cardiovascular autonomic activity

\section{Exclusion Criteria}

$\mathrm{H} / \mathrm{O}$ of any cardiovascular disorders

$\mathrm{H} / \mathrm{O}$ of addiction to tobacco, mishri, alcohol etc.

$\mathrm{H} / \mathrm{O}$ any type of medication which can affect cardiovascular autonomic functions.

Written consent was obtained from all the willing participants (pregnant and non-pregnant) before the start of the study. Data comprising of demographic parameters like Name, Age (Years), Height (Foot), Weight (Kg) and Family/ Medical/ Menstrual history were obtained and recorded from all pregnant and non-pregnant participant. Special emphasis was given to findings suggestive of autonomic neuropathy. The immediate heart rate response to standing (30:15 ratio) was measured by automatic "Cardiac Autonomic Neuropathy Analyzer" (CANWIN). Immediate heart rate response to standing or 30:15 ratio $>1.04$ taken as normal and reduced if $30: 15$ ratio $<1.03 .{ }^{8}$

\section{Statistical analysis}

Statistical analyses were done by one way ANOVA between the study groups control and cases. The p-value $<0.05$ was taken as significant and the p-value $>0.05$ was taken as nonsignificant.

\section{RESULTS}

Table 1 and Figure 1 Shows a comparison of anthropometric parameters results between non-pregnant and $1^{\text {st }}, 2^{\text {nd }}$ and $3^{\text {rd }}$ trimesters of pregnancy. There was no significant difference in the parameters age, height and $\mathrm{Hb}$ in pregnant and nonpregnant women $(\mathrm{P}>0.05)$. But weight shows a significant difference during the $2^{\text {nd }}$ and $3^{\text {rd }}$ trimester when compared with non-pregnant women $\left(\mathrm{P}<0.05^{*}\right)$.

Table $2 \&$ figure 2 shows mean and SD values of immediate heart rate response to standing in pregnant and non-pregnant women.

Table 3 shows the comparison of immediate heart response to standing in pregnant and non-pregnant women. A significant decrease in immediate heart response to standing observed in non-pregnant women and pregnant women of all three trimesters $(\mathrm{p}<0.05)$. 


\section{DISCUSSION}

The present case-control observational study was carried out in the Department of Physiology in collaboration with the Obstetrics and Gynecology department at Rural Medical College Loni from India. The four hundred eighty women aged from 20 to 30 years without any recent history of cardiorespiratory diseases were selected. Among the total participant, three hundred sixty were pregnant in the case group and one hundred twenty were non-pregnant in the control group. Immediate heart rate response to standing was evaluated in all the pregnant and non-pregnant women. Mean and SD of control, $1^{\text {st }}, 2^{\text {nd }}$ and $3^{\text {rd }}$ trimesters of pregnant groups were $1.15 \pm 0.12,1.13 \pm 0.18,1.11 \pm 0.28$ respectively. In a non-pregnant woman, the immediate heart rate response to standing was $1.08 \pm 0.1$. Heart rate response to standing was decreased in pregnant woman and it goes on decreasing as the pregnancy advances. A significant decrease in immediate heart rate response to standing was observed among pregnant women of all trimesters as compared to non-pregnant women.

Similar results are observed by some other researchers. A case-control study by Steven L Clark et al. on ten pregnant women and ten healthy non-pregnant women found a significant decrease in immediate heart rate response to standing among pregnant and non-pregnant women. Though the sample size of the study was less as compared to the present study results observed in both studies were similar. Steven L Clark et al. concluded that there is a blunted heart rate response to immediate standing during pregnancy which results in decreased heart rate and it goes on further decreasing as the gestational age advances. ${ }^{5}$ In other studies by Pyorala $\mathrm{T}$ et al. on sixty pregnant women during the $1^{\text {st }}$ and $2^{\text {nd }}$ trimester found heart rate response to immediate standing changed in both the groups and response was more sluggish with the advancement of pregnancy. ${ }^{9}$ The hemodynamic profile of the pregnant woman is supposed to be altered by changes in position, the effect of the growing fetus and enlarged uterus on vena cava and aortic blood flow in the supine position. ${ }^{10}$ The human response to orthostasis is complex. It is due to sudden pooling in the veins of the leg after standing it causes a fall in the central venous return (preload) and fall in blood pressure which ultimately result in increased heart rate. ${ }^{11}$

Thomas et al. in a study on 143 pregnant women in the $3^{\text {rd }}$ trimester found a reduced difference between standing heart rate and resting heart rate. ${ }^{12}$ In one other study by Nisell et al.found markedly blunted heart rate response to tilting during the last trimester of pregnancy. ${ }^{13}$. All these studies found either blunted response to heart rate or decreased heart rate response to standing during pregnancy and were in agreement with the present study. But few studies were not in agreement with the present study and doesn't found a significant change in immediate heart rate response to stand- ing in pregnant and non-pregnant women. No significant change in immediate heart rate response to standing between pregnant and non-pregnant women. ${ }^{14}$ Similarly one other study by Page et al. doesn't found any significant change in heart rate between pregnant and non-pregnant women and were in non-agreement with the present study. A study by Arpita Mandal et al. on 276 healthy pregnant women from India found that serum progesterone level increase gradually throughout pregnancy and these changes in hormonal levels may also contribute to the altered autonomic functions during pregnancy. ${ }^{15}$

These differences in observations may be due to recruitment of a different group of pregnant women for study as we included subjects from all the three trimesters of pregnancy but in these studies subject from particular trimester were recruited like Ekholm et al. done study on pregnant subjects from $2^{\text {nd }}$ trimester only. These changes are more significant with the advancement of pregnancy and this may be the reason for differences in the findings. The strength of the present study was subjected to all trimesters included in the study. The number of subjects in both pregnant and nonpregnant women was sufficiently large.

Limitations of the present study were the subjects mainly belongs to the rural population and the result cannot be applied to the general population. Subjects visiting for routine checkup were selected and due to proper medical supervision from early pregnancy observed result may vary when compared to subjects with no routine checkup during pregnancy.

\section{CONCLUSION}

The study showed a significant decrease in immediate heart response to standing in the normal pregnant women as compared to non-pregnant women from the rural population of India. A study of parasympathetic functions must be done to predict any pre-existing autonomic dysfunction during pregnancy.

Ethical Approval: The study was carried out after the approval from Institutional Ethics Committee with Registration No. PMT/PIMS/RC/2013/226.

\section{ACKNOWLEDGEMENT}

The authors acknowledge the immense help received from the scholars whose articles are cited and included in the references of the manuscript. The authors are also grateful to authors/editors. Publishers of all those articles, journals and books from where the literature for this article has been reviewed and discussed. All those who have significantly contributed in this study are included as an author. All the authors sincerely pay gratitude to all the patients and healthy 
subjects who have given their blood for analysis and actively participated in the study.

\section{Conflict of Interest: None}

Source of Funding: NIL

\section{REFERENCES}

1. Clapp JF, Seaward BL, Sleamaker RH, Hauser J. Maternal physiologic adaptation to early human pregnancy. Am J Obstet Gynecol 1988;159:1456-1460.

2. Kuo CD, Chen GY, Yang MJ, Lo HM, Tsai YS. Biphasic changes in autonomic nervous activity during pregnancy. $\mathrm{Br} \mathrm{J}$ Anaesth 2000;84:323-329

3. Heiskanen N, Saarelainen H, Valtonen P, Lyyra-Laitinen T, Laitinen T, Vanninen E, Blood pressure and heart rate variability analysis of orthostatic challenge in normal human pregnancies. Clin Physiol Funct Imaging 2008;28:384-390.

4. Souma ML, Cabaniss CD, Nataraj A, Khan Z. The Valsalva manoeuvre: A test of autonomic nervous system functions in pregnancy. Am J Obstet Gynecol 1983;145(3):274-278.

5. Clark SL, Cotton DB, James MP, Lee W, Gary DVH, Thomas JB. Position change and central hemodynamic profile during normal third-trimester pregnancy and postpartum. Am J Obstet Gynecol 1991;164:883-887

6. Page MM, Watkin PJ. The heart in diabetes, autonomic neuropathy and cardiomyopathy: Clin Endocrinol Metab 1977;6:377-
388 .

7. Irhan KA. clinical and physiological study of pregnancy in material from northern Sweden. The arterial blood pressure at rest and in orthostatic test during and after pregnancy. Acta Soc Med Upsallicnsis 1960;65:315-325.

8. Pal GK, Pal P, Autonomic function tests. In Textbook of practical physiology. $2^{\text {nd }}$ ed. Hyderabad: University Press (India) Private Limited; 2007;296-304.

9. Pyorala T. Cardiovascular response to the upright position during pregnancy. Am J Obstet Gynecol Scand 1966;45:111-116.

10. Thomas WT, Wessel N, Baumert M, Stepan H, Voss A, Faber R. Longitudinal analysis of heart rate variability in chronic hypertensive pregnancy. Hypertens Res 2005;28:113-118.

11. Panja S. A study of cardiovascular autonomic function in normal pregnancy: Al-Am J Med Sci 2013;6(2):170-175

12. Thomas RE, Barbara CS, Thomas JB. The hemodynamic effects of orthostatic stress during pregnancy. Obstet Gynecol 1988;72:550-552.

13. Nisell H, Hjemdahl P, Birgitta L, Lunell NO. Sympathoadrenal and cardiovascular reactivity in pregnancy-induced hypertension. Responses to tilting. Am J Obstet Gynecol 1985; 152:554560 .

14. Ekholm EMK, Piha SJ, Erkkola RU, Antila KJ. Autonomic cardiovascular reflexes in pregnancy. A longitudinal study. Clin Auton Res 1994; 4:161-165.

15. Mandal A, Sinha S, Gupta S, Chakraborty S. Estimation of Reference Interval of Serum Progesterone During Three Trimesters of Normal Pregnancy in a Tertiary Care Hospital of Kolkata. Int J Curr Res Rev 2021;12(09):1-4.

Table 1: Anthropometric parameters between non-pregnant and pregnant women

\begin{tabular}{lcccc} 
Parameters & $\begin{array}{c}\text { Non-pregnant } \\
\text { Mean } \pm \text { SD }\end{array}$ & $\mathbf{1}^{\text {st }}$ trimester & $2^{\text {nd }}$ trimester & $3^{\text {rd }}$ trimester \\
Mean \pm SD & Mean \pm SD & Mean \pm SD \\
Age (year) & $23.40 \pm 3.37$ & $23.18 \pm 3.65$ & $22.39 \pm 2.33$ & $23.35 \pm 2.69$ \\
Height (foot) & $5.13 \pm 4.81$ & $5.13 \pm 4.82$ & $5.15 \pm 5.05$ & $5.12 \pm 4.95$ \\
Weight (Kg) & $49.30 \pm 5.66$ & $48.64 \pm 5.60$ & $52.16 \pm 6.64^{*}$ & $58.01 \pm 5.62^{*}$ \\
Weeks of Gestations & ---- & $8.85 \pm 1.77$ & $20.45 \pm 3.87$ & $33.94 \pm 2.99$ \\
Hb (gm/dl) & $11.14 \pm 0.68$ & $11.50 \pm 0.45$ & $10.70 \pm 0.41$ & $10.85 \pm 0.44$ \\
\hline
\end{tabular}

Table 2: Mean and SD values for immediate heart rate response to standing (30:15 ratio)

\begin{tabular}{|c|c|c|c|c|c|c|c|c|}
\hline \multirow[t]{2}{*}{ Test } & \multicolumn{2}{|c|}{$\begin{array}{c}\text { Non-pregnant } \\
n=120\end{array}$} & \multicolumn{2}{|c|}{$\begin{array}{l}1^{\text {st }} \text { Trimester } \\
n=120\end{array}$} & \multicolumn{2}{|c|}{$\begin{array}{l}2^{\text {nd }} \text { Trimester } \\
n=120\end{array}$} & \multicolumn{2}{|c|}{$\begin{array}{c}3^{\text {rd }} \text { Trimester } \\
n=120\end{array}$} \\
\hline & Mean & SD & Mean & SD & Mean & SD & Mean & SD \\
\hline (30:15 ratio) & 1.15 & 0.12 & 1.13 & 0.13 & 1.12 & 0.12 & 1.08 & 0.13 \\
\hline
\end{tabular}

Table 3: Comparison of immediate heart rate response to standing between different trimester of pregnancy and non-pregnant

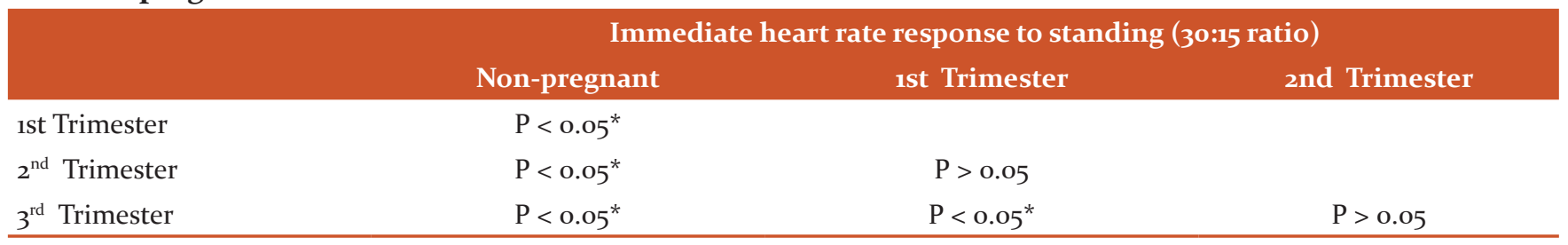

